\title{
Neurology outreach clinic for Huntington disease in Peru
}

Lessons for neurodegenerative diseases

Anastasia Vishnevetsky, MD, Maryenela Illanes-Manrique, MD, Miguel Inca-Martinez, BS, Karina Milla-Neyra, BS, Elison Sarapura-Castro, MD, Pilar Mazzetti, MD, and Mario Cornejo-Olivas, MD

Neurology ${ }^{\circledR}$ 2018;91:282-285. doi:10.1212/WNL.0000000000005940
Correspondence

Dr. Vishnevetsky

staseyvi@gmail.com

With increasing life expectancies worldwide, providing longitudinal care for patients with neurodegenerative diseases in low-resource settings is a growing challenge. ${ }^{1}$ According to the 2015 Global Burden of Disease Study, Alzheimer disease, other dementias, and Parkinson disease together affect more than 50 million people globally. ${ }^{2}$ Furthermore, the WHO estimates that at least $60 \%$ of these cases occur in low and middle-income countries. ${ }^{1}$ Although currently available treatments for neurodegenerative diseases are largely supportive rather than curative, they can reduce morbidity and burden of disease. ${ }^{1}$ As more effective medications become available and the prevalence of neurodegenerative disease increases, the need for skilled care providers will also increase.

Outreach clinics, which deliver specialty-level care to geographically remote areas, have been used for vaccination campaigns, HIV control, and obstetrics, as well as neurologic conditions like epilepsy and stroke. However, these clinics have not been used for the management of neurodegenerative diseases, which occur worldwide but at higher rates in populations bearing specific genetic risks. For example, Huntington disease (HD), a fatal hereditary neurodegenerative disease, is particularly prevalent around Lake Maracaibo in Venezuela and in the Cañete Valley of Peru. ${ }^{3}$ In this report, we present our experience with an outreach clinic focused on HD in Peru, with lessons that may be broadly applicable to neurodegenerative disease care in rural, low-resource settings.

\section{The outreach neurology clinic program}

The Neurogenetics Research Center (NRC) of the Instituto Nacional de Ciencias Neurológicas (INCN) developed an outreach clinic for the rural Cañete valley, where HD prevalence is 4-fold greater than the global rate. ${ }^{3}$ Cañete valley is only a 3-hour drive from the capital city of Lima; however, it has limited available medications, basic health infrastructure, and a single neurologist for more than 100,000 people. Many local patients with HD are unable to access care in Lima due to the expense of travel and mobility limitations, which worsen with disease progression. Notwithstanding the lack of medical personnel in Cañete, Peru is an uppermiddle-income country and has multiple existing neurology residencies that make it possible to staff an outreach clinic.

The initial approach to the Cañete HD community was informed by an earlier incident that compromised trust in outsiders coming to focus on HD. In 2005, journalists, accompanied by some doctors and researchers, came to Cañete to interview and document the experience of HD families. Patients and their families, including children, were photographed without obtaining appropriate consent or informing the families what would be done with the photographs and information. The resulting journalistic piece was a sensationalistic and stigmatizing piece called "The Curse of Cañete," ${ }^{4}$ which described how whole families are affected by

From the Neurogenetics Research Center (A.V., M. Illanes-Manrique, M. Inca-Martinez, K.M.-N., E.S.-C., P.M., M.C.-O.), Instituto Nacional de Ciencias Neurológicas, Lima, Peru; NIH Northern Pacific Fogarty Global Health Fellow (A.V., M. Illanes-Manrique, E.S.-C.), Bethesda, MD; Partners Neurology Residency (A.V.), Boston, MA; and School of Medicine (P.M.), Universidad Nacional Mayor de San Marcos, Lima, Peru.

Go to Neurology.org/N for full disclosures. Funding information and disclosures deemed relevant by the authors, if any, are provided at the end of the article. 
HD, how it occurs at a high prevalence in people from Cañete (implying that contact with people from the area could bring about the curse), and quoted a doctor saying that these people should have never married. It also used original patient and family member names and displayed unflattering photographs. The piece ran in Cañete as well as Lima, and many of the HD patients and families felt betrayed by the journalists as well as the researchers, doctors, and community agents that had facilitated the journalists' access. This history led the NRC team to prioritize community buy-in and engage a local community agent for outreach, institute strict consent processes for genetic testing as well as any research protocols, limit photography, and be more judicious in bringing outside visitors to the outreach clinics.

The outreach clinic consists of 2-day visits to Cañete every 3 months, which have been conducted since 2014 by a multidisciplinary group of health care providers (neurologists, psychiatrists, geneticists, residents, students, and support personnel) traveling from Lima. They divide into 2 teams, with one attending to patients at a local community health center, and the other conducting house visits for homebound patients throughout the region (figure). During the trips, the outreach clinic staff provides neurologic and psychiatric consultations and follow-up visits, distributes medication brought from Lima, takes samples for genetic testing, and provides counseling and family support. Patients (or occasionally their family members) come back to each outreach clinic for medication refills and follow-up, and there are some new patients, as well as some deaths and losses to follow-up. Clinic personnel conduct HD-related training for caregivers and local health care providers and recruit participants for ongoing research. Although the clinic focuses on $\mathrm{HD}$, about half of the patients have other neurodegenerative conditions such as Parkinson disease, ataxia, or dementia (figure).

This program is financially supported by local public-private collaboration. The public component is funded through resources provided by the INCN (van transportation, laboratory supplies, excused hours for contracted members of the NRC team), the Cañete regional health system (meals and lodging), and the government health insurance, Seguro Integral de Salud (SIS) (provides medicines for almost half of the patients). The private component consists of medication donations from local pharmaceutical dispensaries for patients who do not have SIS, as well as volunteer time and funds from the NRC team (other meals, office supplies). Official summaries of the clinic activities, services, and finances are generated for the regional government within a few weeks of each clinic's completion. The data in the figure were generated from 7 summary reports for the 18-month period from March 2015 to October 2016.

\section{Lessons from the outreach clinic experience}

The outreach clinic provides many lessons that may be applicable for similar chronic conditions:

1. Neurodegenerative disease care requires consistent followup (table, excerpt 1). Many neurologic drugs require

Figure Clinic resources, structure, and services

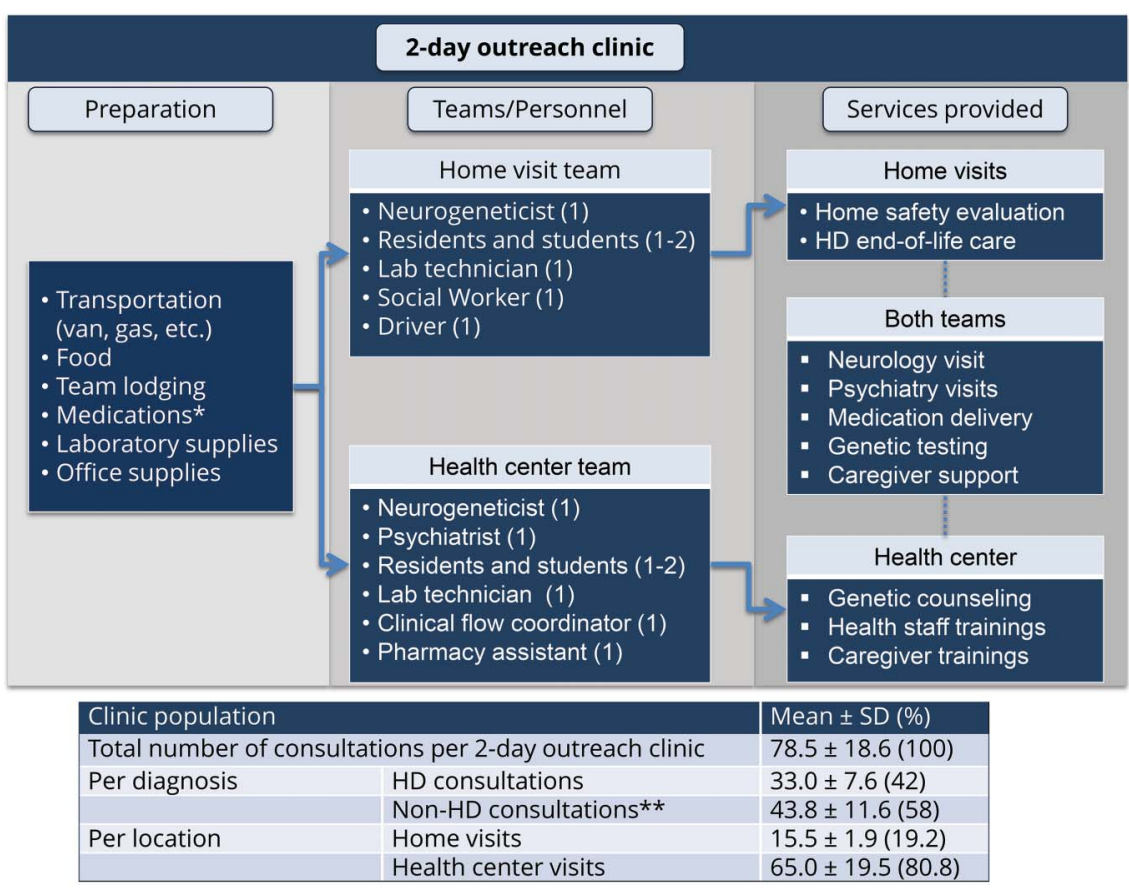

*Medications typically include antipsychotics (risperidone, olanzapine, haloperidol), selective serotonin reuptake inhibitors (citalopram, sertraline), benzodiazepines (clonazepam), carbidopa-levodopa, valproate, topiramate, and others. **Parkinsonism, dementia, ataxias, headache, epilepsy, neurodevelopmental disorders. HD = Huntington disease. 
Table Huntington disease (HD) patient vignettes and caregivers' perspective on outreach clinic

\section{Patient vignettes}

A 31 -year-old woman with aggressive HD psychosis, locked in her room for safety by family. Able to interact with family and come out of the house after 9 months of treatment with second-generation antipsychotics and psychiatric consultations.

A 42-year-old man with HD, moderate chorea, falls, and debilitating depression. Able to return to work on his farm and maintain status as breadwinner for family with young children after 6 months of treatment with second-generation antipsychotics and antidepressants.

A 4-year-old boy with juvenile HD, severe developmental delay, ataxia, and constant, daily seizures. With antiepileptic medications and frequent follow-up, seizures were controlled for 6 months.

\begin{tabular}{ll}
\hline Topic $^{\mathbf{a}}$ & Interview excerpts $^{\mathbf{b}}$ \\
\hline 1. Importance of consistent access & Caregiver: I have to wait 2 months for when you come with the campaign so you can see him. \\
& But in those 2 months, things can happen and I have to wait. As I've said, the disease, it's not that \\
& you come with the campaign and that's it, and you are good, no the disease is constant...We should \\
have...everyone who has a family member with this condition, someone specialized 24 hours per day.
\end{tabular}

2. Preference for home visits

3. Role of social worker

4. Appreciation for outreach clinic
Interviewer: Would you prefer to have doctor's visits here in your home or in the health center?

Caregiver: It's better that they come to my house.

Caregiver: Today I think the (social worker) from the health center sent me a message to bring him. I communicated this to his brothers and he said, ok, bring him.

Caregiver: At least now there are more campaigns, no? For example they come to the house, visit him, give him medicine, and do the evaluation, no? Of every medicine, to see if he has progressed or has not progressed, no? In this respect it's good what they are doing now.

Caregiver: Since in the farm we do not have money available...so it costs for a medical visit, it costs too much. And the pills are very expensive. These tablets...we earn 30, 40 soles in the field...it's very hard.

a Formal qualitative analysis, with thematic saturation of outreach clinic-related topics in interviews, coding, and theme development, were not conducted; topics represent common sentiments expressed via personal communications and in response to exploratory questions about the outreach clinic.

${ }^{b}$ Interview audio recordings were professionally transcribed, and relevant excerpts were translated from Spanish and edited for clarity. The interview guide included questions such as "What are the strengths and drawbacks of the outreach clinics?" or "What additional services could help you face HD?" Quotations were originally acquired for a larger study on quality of life in Huntington disease, which received institutional review board approval from the Instituto Nacional de Ciencias Neurológicas and required written informed consent from all participants. ${ }^{5}$

titration, close monitoring for potentially dangerous side effects, and tapering before discontinuation. Individual physicians have come to the Cañete region in the past and sporadically treated patients with $\mathrm{HD}$ with harmful results: for example, free samples of expensive medications were distributed, but when the supply ran out, families would go to desperate measures, even selling their farms to temporarily obtain the drug.

2. Home visits are a vital part of outreach clinics for neurodegenerative disease (table, excerpt 2). With home visits, we have sometimes arrived to find patients with advanced disease abandoned in unsanitary conditions, bathrooms up a steep staircase, or family unclear on when medications were administered. We have been able to assess a patient's daily life, make environmental adjustments, facilitate alternate caregiving arrangements, or mediate conflicts in a way that would not be possible outside the home.

3. Importance of local social worker or community health worker for outreach (table, excerpt 3 ). The local social worker has contact information for all families, informs them of upcoming outreach clinics, directs the drivers to patient homes in areas without addresses and cell service, and contacts the specialists in Lima between clinics in case of any acute complications. She has known the HD families for over a decade, and her constant presence in Cañete between visits facilitates trust and streamlined clinic coordination.

\section{Challenges and opportunities for the future}

1. Defining measurable outcomes for evaluating the efficacy of an intervention in neurodegenerative disease care. Despite the documented qualitative effect of the program on patients and caregivers (table, excerpt 4), the phenotypic heterogeneity of neurodegenerative conditions makes it difficult to establish precise and objective outcome measures for the program. In $\mathrm{HD}$, for example, clinical improvement due to proper management can manifest in a myriad of ways that are hard to quantify: extra years of employment, fewer falls, control of behavioral disturbances, or decreased caregiver burden. HD-specific health-related quality of life questionnaires are currently being validated in the Peruvian population and hold promise for future outcome evaluations.

2. Developing local health capacity for neurodegenerative disease care and expanding interdisciplinary involvement. We have been holding regular trainings and lectures with local health care providers, but it has not yet been feasible 
for them to make medical decisions regarding HD care. In addition, although we have genetics, psychiatry, neurology, nursing, and social work on our team, we have yet to involve nutritionists, geriatricians, or physical therapists in the outreach clinic.

3. Obtaining sustainable funding. The public-private outreach clinic funding model allows for integration into the existing Peruvian health system and provision of care for the poorest patients (table, excerpt 5). However, significant bureaucracy and personnel changes in government sometimes generate unpredictability in funding. International funding and more extensive collaboration with local nongovernmental organizations would provide more stability and allow the clinics to grow.

Although HD and other neurodegenerative diseases are not typically considered a priority in low-resource settings, their effect on patients, families, and the surrounding community can be devastating. The strategies used in this Peruvian neurology outreach clinic model can be replicated to provide much-needed specialty care for patients with neurodegenerative disorders in low-resource and remote settings throughout the globe.

\section{Author contributions}

Anastasia Vishnevetsky: study concept and design, analysis and interpretation of data, critical revision of manuscript for intellectual content. Maryenela Illanes Manrique: acquisition of data, critical revision of manuscript for intellectual content. Miguel Inca-Martinez, acquisition of data, critical revision of manuscript for intellectual content. Karina Milla-Neyra: acquisition of data, critical revision of manuscript for intellectual content. Elison Sarapura-Castro: analysis and interpretation of data, critical revision of manuscript for intellectual content. Pilar Mazzetti-Soler: study supervision, critical revision of manuscript for intellectual content. Mario Cornejo-Olivas: study concept and design, critical revision of manuscript for intellectual content.

\section{Acknowledgment}

The authors thank Ana Mascaro and Carmen Vicente for their work for the outreach clinics at the Centro de Salud "Nuevo Imperial" Cañete; Victoria Marca and Olimpio Ortega for assistance with the administration and laboratory functioning of the clinics and all the neurology residents who have made the clinic possible; and Claudia Gambrah-Sampaney, Dr. Thomas Bird, Dr. Joseph Zunt, Dr. Farrah Mateen, Dr. Neha Limaye, and Danielle Rabinowitz for critical review and comments on the manuscript.

\section{Study funding}

Research training for A.V., M. Illanes-Manrique, and E.S.-C. was supported by NIH Research Training grant \#R25 TW009345 funded by the Fogarty International Center, the NIH Office of the Director, Office of AIDS Research, the NIH Office of the Director Office of Research on Women's Health, the National Heart, Lung, and Blood Institute, the National Institute of Mental Health, and the National Institute of General Medical Sciences.

\section{Disclosure}

The authors report no disclosures relevant to the manuscript. Go to Neurology.org/N for full disclosures.

\section{References}

1. World Health Organization. First WHO ministerial conference on global action against dementia: meeting report, 16-17 March, 2015; Geneva: WHO; 2015.

2. GBD 2015 Neurological Disorders Collaborator Group. Global, regional, and national burden of neurological disorders during 1990-2015: a systematic analysis for the global burden of disease study 2015. Lancet Neurol 2017;16:877-897.

3. Cornejo-Olivas M, Espinoza-Huertas K, Velit-Salazar MR, et al. Neurogenetics in Peru: clinical, scientific and ethical perspectives. J Community Genet 2015;6: 251-257.

4. Loayza J. La maldicion de cañete. La Republica 2005;43.

5. Vishnevetsky A, Illanes-Manrique M, Inca-Martinez M, Cornejo-Olivas M. Myths and misconceptions regarding Huntington's disease in Peru. Mov Disord 2017; 32(suppl 2).

\section{Committed to Making a Difference: 2019 American Academy of Neurology Research Program}

The American Academy of Neurology (AAN) is committed to making a profound difference in the lives of researchers, in turn making a difference in the lives of patients with brain disease. The ambitious 2019 AAN Research Program offers opportunities ranging from $\$ 130,000$ to $\$ 450,000$ and designed for all types of research across all career levels and discovery stages. Pave your own pathway to patient care by applying for one of the opportunities by the October 1, 2018, deadline.

Visit AAN.com/view/ResearchProgram today. 


\section{Neurology}

\section{Neurology outreach clinic for Huntington disease in Peru: Lessons for neurodegenerative diseases}

Anastasia Vishnevetsky, Maryenela Illanes-Manrique, Miguel Inca-Martinez, et al.

Neurology 2018;91;282-285 Published Online before print July 6, 2018

DOI 10.1212/WNL.0000000000005940

\section{This information is current as of July 6, 2018}

\section{Updated Information \& Services}

References

Subspecialty Collections

\section{Permissions \& Licensing}

Reprints including high resolution figures, can be found at: http://n.neurology.org/content/91/6/282.full

This article cites 2 articles, 0 of which you can access for free at: http://n.neurology.org/content/91/6/282.full\#ref-list-1

This article, along with others on similar topics, appears in the following collection(s):

Access to care

http://n.neurology.org/cgi/collection/access_to_care All Cognitive Disorders/Dementia

http://n.neurology.org/cgi/collection/all_cognitive_disorders_dementia All global neurology

http://n.neurology.org/cgi/collection/all_global_neurology

Huntington's disease

http://n.neurology.org/cgi/collection/huntingtons_disease

Medical care

http://n.neurology.org/cgi/collection/medical_care

Information about reproducing this article in parts (figures,tables) or in its entirety can be found online at:

http://www.neurology.org/about/about_the_journal\#permissions

Information about ordering reprints can be found online:

http://n.neurology.org/subscribers/advertise

Neurology ${ }^{\circledR}$ is the official journal of the American Academy of Neurology. Published continuously since 1951, it is now a weekly with 48 issues per year. Copyright () 2018 American Academy of Neurology. All rights reserved. Print ISSN: 0028-3878. Online ISSN: 1526-632X.

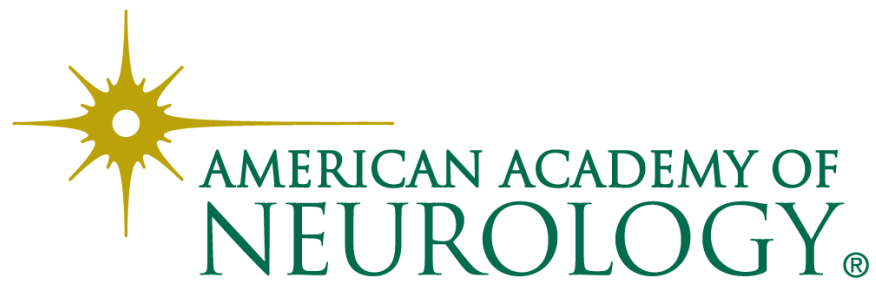

